\title{
Imaging the Impact of the P-Glycoprotein (ABCB1) Function on the Brain Kinetics of Metoclopramide
}

\author{
Géraldine Pottier $^{1,2}$, Solène Marie ${ }^{1,2}$, Sébastien Goutal ${ }^{1,2}$, Sylvain Auvity ${ }^{1,2}$, Marie-Anne Peyronneau ${ }^{1,2}$, Simon Stute ${ }^{1,2}$, \\ Raphaël Boisgard ${ }^{1,2}$, Frédéric Dollé ${ }^{1,2}$, Irène Buvat ${ }^{1,2}$, Fabien Caillé $^{1,2}$, and Nicolas Tournier ${ }^{1,2}$ \\ ${ }^{I}$ Inserm/CEA/Université Paris Sud, UMR 1023 - ERL 9218 CNRS, IMIV, Orsay, France; and ${ }^{2}$ CEA, DSV, I2BM, Service Hospitalier \\ Frédéric Joliot, Orsay, France
}

The effects of metoclopramide on the central nervous system (CNS) in patients suggest substantial brain distribution. Previous data suggest that metoclopramide brain kinetics may nonetheless be controlled by ATP-binding cassette (ABC) transporters expressed at the blood-brain barrier. We used ${ }^{11} \mathrm{C}$-metoclopramide PET imaging to elucidate the kinetic impact of transporter function on metoclopramide exposure to the brain. Methods: ${ }^{11} \mathrm{C}$-metoclopramide transport by P-glycoprotein (P-gp; $A B C B 1$ ) and the breast cancer resistance protein (BCRP; ABCG2) was tested using uptake assays in cells overexpressing P-gp and BCRP. ${ }^{11} \mathrm{C}$-metoclopramide brain kinetics were compared using PET in rats $(n=4-5)$ in the absence and presence of a pharmacologic dose of metoclopramide ( $3 \mathrm{mg} / \mathrm{kg})$, with or without P-gp inhibition using intravenous tariquidar $(8 \mathrm{mg} / \mathrm{kg})$. The ${ }^{11} \mathrm{C}$-metoclopramide brain distribution $\left(\mathrm{V}_{\mathrm{T}}\right.$ based on Logan plot analysis) and brain kinetics (2-tissue-compartment model) were characterized with either a measured or an imaged-derived input function. Plasma and brain radiometabolites were studied using radio-high-performance liquid chromatography analysis. Results: ${ }^{11} \mathrm{C}$-metoclopramide transport was selective for P-gp over BCRP. Pharmacologic dose did not affect baseline ${ }^{11} \mathrm{C}$-metoclopramide brain kinetics $\left(\mathrm{V}_{\mathrm{T}}=2.28 \pm\right.$ 0.32 and $2.04 \pm 0.19 \mathrm{~mL} \cdot \mathrm{cm}^{-3}$ using microdose and pharmacologic dose, respectively). Tariquidar significantly enhanced microdose ${ }^{11} \mathrm{C}$-metoclopramide $\mathrm{V}_{\mathrm{T}}\left(7.80 \pm 1.43 \mathrm{~mL} \cdot \mathrm{cm}^{-3}\right)$ with a 4.4 -fold increase in $K_{1}$ (influx rate constant) and a 2.3 -fold increase in binding potential $\left(k_{3} / k_{4}\right)$ in the 2 -tissue-compartment model. In the pharmacologic situation, $\mathrm{P}$-gp inhibition significantly increased metoclopramide brain distribution $\left(\mathrm{V}_{\mathrm{T}}=6.28 \pm 0.48 \mathrm{~mL} \cdot \mathrm{cm}^{-3}\right)$ with a 2.0-fold increase in $K_{1}$ and a 2.2-fold decrease in $k_{2}$ (efflux rate), with no significant impact on binding potential. In this situation, only parent ${ }^{11} \mathrm{C}$-metoclopramide could be detected in the brains of $\mathrm{P}$-gp-inhibited rats. Conclusion: ${ }^{11} \mathrm{C}$-metoclopramide benefits from favorable pharmacokinetic properties that offer reliable quantification of $\mathrm{P}$-gp function at the blood-brain barrier in a pharmacologic situation. Using metoclopramide as a model of CNS drug, we demonstrated that $\mathrm{P}$-gp function not only reduces influx but also mediates the efflux from the brain back to the blood compartment, with additional impact on brain distribution. This PET-based strategy of $\mathrm{P}$-gp function investigation may provide new insight on the contribution of P-gp to the variability of response to CNS drugs between patients.

\footnotetext{
Received Jul. 30, 2015; revision accepted Nov. 2, 2015.

For correspondence or reprints contact: Nicolas Tournier, CEA, DSV, I2BM, Service Hospitalier Frédéric Joliot, Orsay, F-91401, France.

E-mail: nicolas.tournier@cea.fr

Published online Nov. 19, 2015.

COPYRIGHT (c) 2016 by the Society of Nuclear Medicine and Molecular Imaging, Inc.
}

Key Words: ${ }^{11} \mathrm{C}$-metoclopramide; breast cancer resistance protein; ABC transporter; blood-brain barrier; microdose

J Nucl Med 2016; 57:309-314

DOI: 10.2967/jnumed.115.164350

$\mathbf{T}$ he identification of P-glycoprotein (P-gp, MDR1, ABCB1) at the luminal side of the brain capillaries forming the bloodbrain barrier (BBB) raised important questions regarding the exposure of many drugs to the brain (1). PET imaging is an appealing and noninvasive approach to study the functional impact of transporters at the human BBB (2). P-gp function at the human $\mathrm{BBB}$ was first unveiled using ${ }^{11} \mathrm{C}$-verapamil, a radiolabeled P-gp substrate (3). Unfortunately, ${ }^{11} \mathrm{C}$-verapamil radiometabolites complicate PET data analysis because some of these radiometabolites can freely cross the $\mathrm{BBB}$, whereas others interact with P-gp (4). ${ }^{11} \mathrm{C}-\mathrm{N}$-desmethyl-loperamide, which is a metabolite of loperamide, is another avid P-gp substrate with improved metabolic stability in vivo (5). These specific PET radiotracers have shown that P-gp restricts the brain uptake $\left(K_{1}\right.$; influx rate constant) of its substrates, thus limiting their exposure to the brain (6). However, it was recently suggested that microdose studies may not reflect the impact of transporters on drug brain kinetics in the pharmacologic situation (7).

Preclinical and invasive studies suggest that P-gp function may also actively control the efflux of its substrates from the brain back to the plasma (8). In addition to limiting the influx, efflux enhancement may differentially affect the overall exposure of P-gp substrate to the brain (9). Because of limited baseline uptake (in the presence of P-gp) or the presence of brain radiometabolites, available PET radioligands do not allow for accurate estimation of the brain efflux constant $\left(k_{2}\right)$. Therefore, alternative PET radiotracers with optimized pharmacokinetic properties are needed to investigate the $k_{2}$ component of $\mathrm{P}$-gp function and its overall contribution to the brain distribution $\left(\mathrm{V}_{\mathrm{T}}\right)(6,10)$.

Many drugs targeting the central nervous system (CNS), including some antiepileptic drugs (11), opioids (12), antidepressants, or neuroleptics (13), have been identified as moderate P-gp substrates in vitro with substantial baseline brain distribution in vivo. Metoclopramide intravenous formulation is commonly prescribed as an antiemetic (14). In patients, reported effects of metoclopramide on the CNS suggest substantial baseline brain distribution (14). Metoclopramide was shown to cross the BBB in rodents (15). Still, in vitro studies have shown that metoclopramide is a moderate substrate of both the human and the rodent P-gp (16). 
In the present study, we used ${ }^{11} \mathrm{C}$-metoclopramide to understand how P-gp affects the brain kinetics of metoclopramide, which serves as a model of P-gp substrate with substantial baseline brain uptake. Specificity toward the breast cancer resistance protein (BCRP, ABCG2) was assessed in vitro. In rats, brain kinetics of microdose and pharmacologic dose ${ }^{11} \mathrm{C}$-metoclopramide were studied in the presence and absence of P-gp inhibition.

\section{MATERIALS AND METHODS}

\section{Animals}

Thirty-five male Wistar rats (Janvier) were used for the study (mean weight $\pm \mathrm{SD}, 322 \pm 23 \mathrm{~g}$ ). Animals were housed and acclimatized for at least $1 \mathrm{wk}$ before the experiment. Rats had free access to rat chow and water. Animal studies were conducted in accordance with the French legislation and European directives on the use of animals in research.

\section{Chemicals}

Tariquidar used for P-gp inhibition was purchased from Eras Labo. Tariquidar solutions for intravenous injection $\left(4.4 \mathrm{mg} \cdot \mathrm{mL}^{-1}\right)$ were prepared the day of the experiment by dissolving tariquidar dimesylate $2.35 \mathrm{H}_{2} \mathrm{O}(\sim 6 \mathrm{mg})$ in a $5 \%(\mathrm{w}: \mathrm{v})$ glucose solution $(0.5 \mathrm{~mL})$ followed by dilution with sterile water $(0.5 \mathrm{~mL})$. Metoclopramide was administered using Metoclopramide Renaudin for intravenous injection (10 $\mathrm{mg} / 2 \mathrm{~mL}$; Renaudin). Ko-143 used for BCRP inhibition was purchased from Sigma-Aldrich. The P-gp inhibitor valspodar (PSC833) was obtained from Novartis.

\section{Radiochemicals}

${ }^{3} \mathrm{H}$-prazosin $(3.15 \mathrm{GBq} / \mu \mathrm{mol})$ used for a model P-gp/BCRP substrate was obtained from Perkin-Elmer. Ready-to-inject, greater than 99\% radiochemically pure ${ }^{11} \mathrm{C}$-metoclopramide (4-amino-5-chloro- $N$ (2-(diethylamino)ethyl)-2- ${ }^{11} \mathrm{C}$-methoxybenzamide) was prepared from cyclotron-produced ${ }^{11} \mathrm{C}$-carbon dioxide (Cyclone-18/9 cyclotron; IBA) and nor-metoclopramide (4-amino-5-chloro- $N$-(2-(diethylamino) ethyl)-2-hydroxybenzamide, from Sanofi) using a TRACERLab FX-C synthesizer (GE Healthcare). Radiomethylation was performed with ${ }^{11} \mathrm{C}$-methyl triflate on the methoxy phenyl moiety of nor-metoclopramide to afford ${ }^{11} \mathrm{C}$-metoclopramide $(11-15 \mathrm{GBq})$ with specific radioactivities ranging from 110 to $150 \mathrm{GBq} / \mu \mathrm{mol}$. Quality controls were performed on an aliquot of the ready-to-inject ${ }^{11} \mathrm{C}$-metoclopramide preparation.

\section{Uptake Assay in P-gp- and BCRP-Overexpressing Cells}

Transfected MDCKII-MDR1 and MDCKII-BCRP cells were obtained from Alfred Schinkel (National Cancer Institute). Cells were seeded onto 24 -well plates $\left(3.10^{5}\right.$ cells/well) and allowed to grow for $3 \mathrm{~d}$. On the day of the experiment, cell monolayers were washed and incubated with buffer containing either ${ }^{11} \mathrm{C}$-metoclopramide $(\sim 10$ $\mathrm{MBq} / \mathrm{mL} ; \sim 0.5 \mu \mathrm{M})$ or the dual P-gp/BCRP substrate ${ }^{3} \mathrm{H}$-prazosin $(\sim 3.7 \mathrm{kBq} / \mathrm{mL} ; 1.1 \mathrm{nM})(17)$ as a positive control. Inhibition of P-gp and BCRP was obtained by adding PSC833 $(5 \mu \mathrm{M})(17)$ and Ko-143 $(10 \mu \mathrm{M})(18)$, respectively, to the incubation buffer. Into control vials was added vehicle (dimethyl sulfoxide, $0.5 \%$ ) instead. After a 30-min incubation, monolayers were washed twice with ice-cold phosphatebuffered saline and lysed during 1 min using $500 \mu \mathrm{L}$ of $\mathrm{NaOH} 0.1 \mathrm{~N}$. Samples $(300 \mu \mathrm{L})$ from each vial were then counted for ${ }^{11} \mathrm{C}$ radioactivity or mixed with Ultima Gold scintillation cocktail (Perkin Elmer) to measure tritium radioactivity. ${ }^{11} \mathrm{C}$-metoclopramide and ${ }^{3} \mathrm{H}$-prazosin radioactivities found in each vial were divided by the mean radioactivity measured in the control vials to estimate the percentage uptake ( $n=6$ in each condition).

\section{Small-Animal PET Imaging}

Experimental Conditions. The brain kinetics of microdose ${ }^{11} \mathrm{C}$-metoclopramide $(39.4 \pm 9.0 \mathrm{MBq} ; 4.3 \pm 3.9 \mu \mathrm{g} / \mathrm{kg} ; 14.5 \pm$ $13.2 \mathrm{nmol} / \mathrm{kg}$ ) was measured either in the absence (condition A, $n=5$ ) or in the presence (condition $\mathrm{B}, n=4$ ) of the P-gp inhibition. Coinjection of ${ }^{11} \mathrm{C}$-metoclopramide with unlabeled metoclopramide $(36.7 \pm 7.9 \mathrm{MBq} ; 3 \mathrm{mg} / \mathrm{kg} ; 10 \mu \mathrm{mol} / \mathrm{kg}$ ) was performed in the absence (condition $\mathrm{C}, n=4$ ) and in the presence (condition $\mathrm{D}, n=5$ ) of P-gp inhibition. P-gp inhibition was obtained using tariquidar $(8 \mathrm{mg} / \mathrm{kg})$ administered intravenously $15 \mathrm{~min}$ before PET.

Three animals in condition D were used for the displacement experiments: they were administered an additional metoclopramide dose of $10 \mathrm{mg} / \mathrm{kg}$ after $30 \mathrm{~min}$ of scanning, which was then continued for $30 \mathrm{~min}$.

Imaging Protocol. PET scans were obtained using an Inveon microPET system (Siemens). Anesthesia was induced and thereafter maintained using 3\% and $1.5 \%-2.5 \%$ isoflurane in $\mathrm{O}_{2}$, respectively. Thirty-minute dynamic scans were acquired, starting from intravenous injection of a bolus ${ }^{11} \mathrm{C}$-metoclopramide with or without unlabeled metoclopramide in a catheter inserted in the caudal lateral vein. Images were reconstructed with the Fourier rebinning algorithm + 2-dimensional ordered-subset expectation maximization algorithm including normalization, attenuation, scatter, and random corrections.

Image analysis and quantification of radioactivity uptake were performed using PMOD software (version 3.5; PMOD Technologies). Regions of interest were drawn manually on the whole brain and in the heart blood-pool to generate the corresponding time-activity curves with time frame durations of $0.25 \mathrm{~min}, 0.5 \mathrm{~min} \times 2,0.75 \mathrm{~min}, 1 \mathrm{~min} \times 4$, $1.5 \mathrm{~min}, 2 \mathrm{~min} \times 4,2.5$ and $3 \mathrm{~min} \times 3$, and $3.5 \mathrm{~min}$. Radioactivity was corrected for ${ }^{11} \mathrm{C}$ decay, injected dose, and animal weight to express the measurements in SUV. $\mathrm{T}_{\max }$, defined as the time at which the maximum of the time-activity curve $\left(\mathrm{SUV}_{\max }\right)$ occurred, was also used to characterize the time-activity curves.

PET Kinetics Modeling. First, PET kinetics modeling was performed using PMOD software and the Logan plot analysis to estimate the total volume of distribution $\left(\mathrm{V}_{\mathrm{T}}\right)$ in a model-independent manner. For each condition, $\mathrm{V}_{\mathrm{T}}$ was estimated using the corresponding metabolite-corrected input function (parent ${ }^{11} \mathrm{C}$-metoclopramide in plasma vs. time, SUV units). Time-activity curves obtained in the heart bloodpool were then used as an input function. Time-activity curves were normalized from plasma activity (imaged-derived blood/measured plasma $=0.3$ for conditions $\mathrm{A}$ and $\mathrm{B}$ and 0.5 for conditions $\mathrm{C}$ and $\mathrm{D}$, respectively) and corrected from radiometabolites using the corresponding parent ${ }^{11} \mathrm{C}$-metoclopramide fraction measured in plasma. ${ }^{11} \mathrm{C}$-metoclopramide volume of distribution $\left(\mathrm{V}_{\mathrm{T}}{ }_{\mathrm{T}}\right)$ was then estimated using the Logan plot. Brain kinetics were also modeled using the 2tissue compartment in each rat to estimate $K_{1}, k_{2}, k_{3}, k_{4}$, and the binding potential $\left(\mathrm{BP}_{\mathrm{ND}}=k_{3} / k_{4}\right)$ in all tested conditions to allow for comparison between conditions.

Arterial Input Function and Brain Metabolites. ${ }^{11} \mathrm{C}$-metoclopramide arterial input function corrected for radiometabolites was measured in dedicated experiments ( $n=3$ for each condition). Plasma samples preparation and radio-high-performance liquid chromatography methodology are described in a supplemental data file (supplemental materials are available at http://tech.snmjournals.org).

Plasma free fraction (not bound to plasma protein) was measured ( $n=3$ in each condition) using a previously described ultrafiltration method (Microcon filtration devices, YM, 10 membrane; Millipore) (19).

Three animals in condition $\mathrm{C}$ were used to study brain radiometabolites. Thirty minutes after injection $(\sim 74 \mathrm{MBq} ; 3 \mathrm{mg} / \mathrm{kg})$, rats were decapitated. To the brains were added $200 \mu \mathrm{L}$ of purified water before sonication at $4{ }^{\circ} \mathrm{C}$. Brain homogenates were mixed with 
$700 \mu \mathrm{L}$ of acetonitrile. The extracts $(400 \mu \mathrm{L})$ were injected onto the radio-high-performance liquid chromatography system (supplemental data).

\section{Statistical Analysis}

Statistical analysis was performed using $\mathrm{R}$ version 3.1.2 (The $\mathrm{R}$ Foundation). In vitro data were compared using 2-way ANOVA analysis. PET data were compared using nonparametric MannWhitney tests for independent data. A result was deemed significant when a 2 -tailed $P$ value was less than 0.05 .

\section{RESULTS}

\section{Uptake Assay in P-gp- and BCRP-Overexpressing Cells}

Figure 1 shows that the accumulation of ${ }^{11} \mathrm{C}$-metoclopramide in $\mathrm{P}$-gp-overexpressing cells is enhanced up to 1.4-fold in the presence of P-gp inhibition. Conversely, ${ }^{11} \mathrm{C}$-metoclopramide accumulation in BCRP-overexpressing cells is not different in the presence of Ko-143, demonstrating metoclopramide specificity for P-gp over BCRP. The accumulation of the positive control ${ }^{3} \mathrm{H}$-prazosin was enhanced up to 2.0 and 2.7 in MDR1- and BCRP-transfected cells, respectively, demonstrating the validity of the model.

\section{Small-Animal PET Imaging}

Figure 2 shows representative PET images of the brain distribution of ${ }^{11} \mathrm{C}$-metoclopramide in the different tested conditions. In all conditions, ${ }^{11} \mathrm{C}$-metoclopramide brain distribution appeared homogeneous within brain parenchyma. Unlabeled metoclopramide (condition $\mathrm{C}$ ) enhanced the brain PET signal, which was even more increased by P-gp inhibition (conditions B and D).

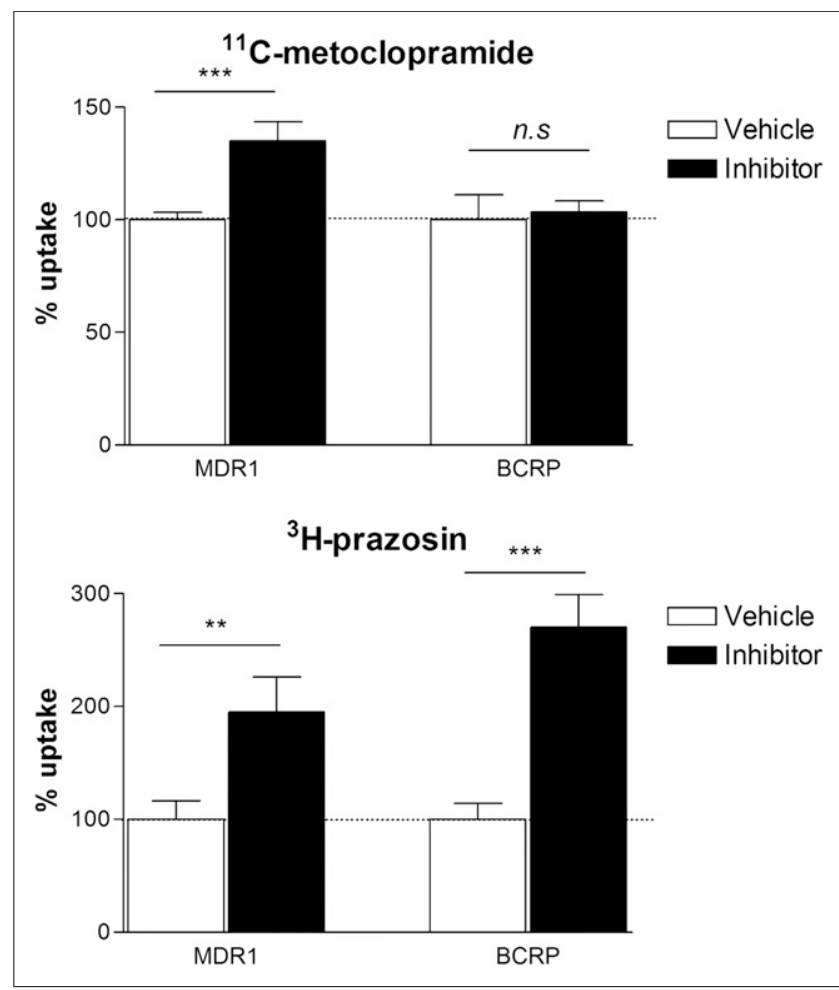

FIGURE 1. ${ }^{11} \mathrm{C}$-metoclopramide uptake assay in MDCKII cells transfected with human MDR1 or BCRP genes. ${ }^{3} \mathrm{H}$-prazosin, a substrate of both P-gp and BCRP, was used as positive control. Accumulation in each vial was normalized by mean uptake in absence of inhibitor. Data are percentage uptake \pm SD $(n=6)$. ${ }^{* \star} P<0.001$. ${ }^{* \star} P<0.01$. n.s $=$ nonsignificant.
Figure 3 displays the corresponding time-activity curves in the brain. At microdose (condition A), brain radioactivity peaked rapidly ( $\mathrm{T}_{\max }, \sim 3 \mathrm{~min} ; \mathrm{SUV}_{\max }, 0.45 \pm 0.05$ ). At pharmacologic dose (condition $\mathrm{C}$ ), brain radioactivity peaked at a higher value $\left(\mathrm{T}_{\max }\right.$, $\sim 2 \mathrm{~min} ; \mathrm{SUV}_{\max }, 0.53 \pm 0.04$ ). Total brain exposure was found to be higher using a pharmacologic dose (area under the time-activity curve from 0 to $\left.30 \mathrm{~min}\left[\mathrm{AUC}_{0-30} \mathrm{~min}\right]=11.88 \pm 1.04 \mathrm{SUV} \cdot \mathrm{min}\right)$ than microdose metoclopramide $\left(\mathrm{AUC}_{0-30} \min =8.57 \pm 1.10\right.$ SUV.min; $P<0.05$ ). In the presence of tariquidar (condition D), a delay in $\mathrm{T}_{\max }$ was observed $(\sim 11 \mathrm{~min})$ with $\mathrm{SUV}_{\max }$ equaling $1.26 \pm 0.11$-that is, 2.4-fold higher than in condition $\mathrm{C}$. This suggests a major impact of P-gp inhibition on the brain kinetics of metoclopramide. As shown in Figure 4, additional displacement using a higher dose of metoclopramide did not decrease ${ }^{11} \mathrm{C}$-metoclopramide brain radioactivity, suggesting predominant nonspecific binding in condition D (Fig. 4).

\section{${ }^{11} \mathrm{C}$-Metoclopramide Arterial Input Function and Metabolism}

Figure 3 shows ${ }^{11} \mathrm{C}$-metoclopramide parent fraction in plasma versus time. Microdose ${ }^{11} \mathrm{C}$-metoclopramide (conditions $\mathrm{A}$ and $\mathrm{B}$ ) was metabolized with parent compound, accounting for $20 \%$ of total plasma radioactivity $30 \mathrm{~min}$ after injection. Coinjection with unlabeled metoclopramide (conditions $\mathrm{C}$ and D) improved parent ${ }^{11} \mathrm{C}$-metoclopramide recovery in plasma (55\% at $30 \mathrm{~min}$ ), suggesting dose-dependent metabolism. ${ }^{11} \mathrm{C}$-metoclopramide free fraction in plasma $\left(f_{\mathrm{P}}\right)$ was not different between conditions (Table 1).

Figure 5 shows representative radiochromatograms of the brain and plasma obtained at 30 min after injection in condition D. Only parent ${ }^{11} \mathrm{C}$-metoclopramide could be detected in the brain at 30 min, suggesting that radiolabeled metabolites of metoclopramide do not detectably cross the BBB, even in the presence of tariquidar.

\section{Pharmacokinetic Modeling}

Table 1 displays the mean outcome parameters obtained using pharmacokinetic modeling in each tested condition. Baseline brain $\mathrm{V}_{\mathrm{T}} \mathrm{s}$ were not significantly different at tracer (condition $\mathrm{A}$ ) and pharmacologic dose (condition $C$ ). P-gp inhibition increased $V_{T}$. The effect of tariquidar on $\mathrm{V}_{\mathrm{T}}$ was higher at microdose than pharmacologic dose (condition B vs. condition D).

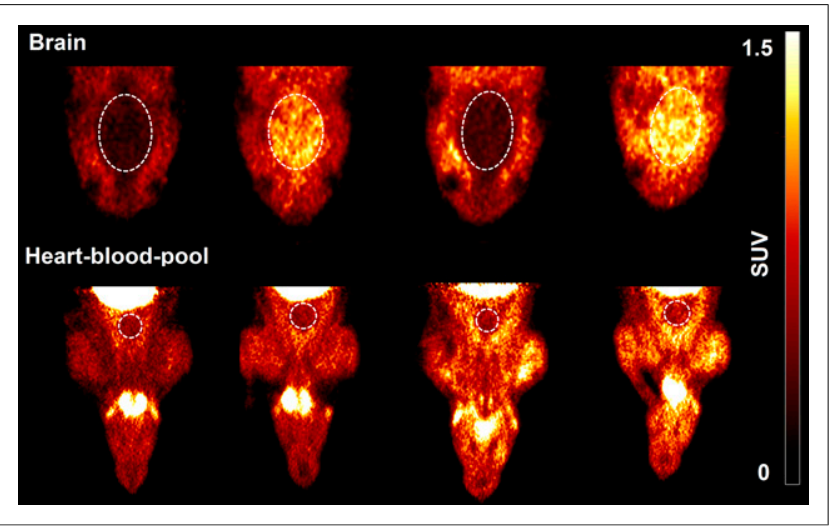

FIGURE 2. Representative PET images (sum from 20 to 30 min after injection, SUV units) obtained using microdose ${ }^{11} \mathrm{C}$-metoclopramide without (condition A) or with P-gp inhibition (condition B) compared with data obtained using metoclopramide $(3 \mathrm{mg} / \mathrm{kg}$ ) coinjection without (condition C) or with (condition D) P-gp inhibition (tariquidar, $8 \mathrm{mg} / \mathrm{kg}$ ). Volumes of interest drawn on brain and heart blood-pool are represented as white dashed lines. 


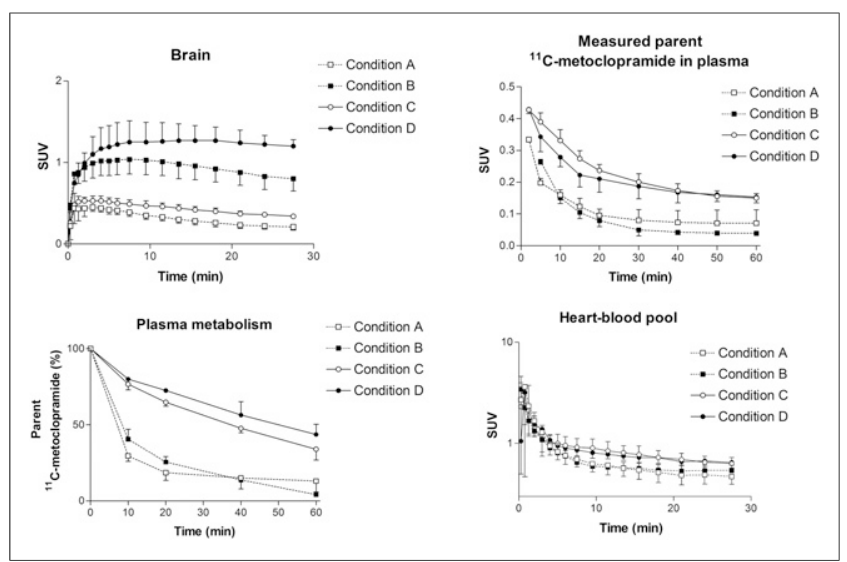

FIGURE 3. ${ }^{11} \mathrm{C}$-metoclopramide PET time-activity curves obtained in brain and heart blood-pool using microdose metoclopramide without (condition A) or with P-gp inhibition (condition B) compared with data obtained using metoclopramide $(3 \mathrm{mg} / \mathrm{kg}$ ) coinjection without (condition C) or with (condition D) P-gp inhibition (tariquidar, $8 \mathrm{mg} / \mathrm{kg}$ ). Respective plasma kinetics of parent ${ }^{11} \mathrm{C}$-metoclopramide in same conditions were obtained from measured arterial input function corrected from parent ${ }^{11} \mathrm{C}$-metoclopramide fraction in plasma.

The fast washout of heart blood-pool radioactivity compared with the brain and surrounding tissues suggests a low tracer uptake by the heart tissue, which was influenced by neither P-gp inhibition nor displacement by high-dose metoclopramide (Figs. 2, 3, and 4). We found a good correlation $\left(R^{2}=0.9388 ; P<0.001\right)$ between $\mathrm{V}_{\mathrm{T}}$ estimated using the arterial input function and $V^{\prime}{ }_{\mathrm{T}}$ estimated using the image-derived input function, suggesting poor contribution of the heart tissue to the heart blood-pool radioactivity (Table 1). In the 2-tissue-compartment model, ${ }^{11} \mathrm{C}$-metoclopramide kinetic parameters $\left(K_{1}, k_{2}, k_{3}\right.$, and $\left.k_{4}\right)$ were not significantly different in the presence and absence of pharmacologic-dose metoclopramide (condition A vs. condition $\mathrm{C}$ ). When microdose was used (conditions $\mathrm{A}$ and $\mathrm{B}$ ), P-gp inhibition increased $K_{1}$ and $\mathrm{BP}_{\mathrm{ND}}$. In the pharmacologic situation (conditions $\mathrm{C}$ and $\mathrm{D}$ ), tariquidar did not affect $\mathrm{BP}_{\mathrm{ND}}$. P-gp inhibition increased $K_{1}$ (2-fold) and decreased $k_{2}$ (2.2-fold).

\section{DISCUSSION}

We used ${ }^{11} \mathrm{C}$-metoclopramide PET imaging to elucidate the functional impact of P-gp on the brain kinetics of metoclopramide, a prototypical P-gp substrate with substantial brain distribution. In vitro studies have shown that metoclopramide is a substrate of the human and rodent P-gp (16). Metoclopramide efflux ratio measured using standardized bidirectional assay in MDCKII-MDR1 cells was found to be 1.4-fold higher than that obtained in MDCKII-parent cells. This ratio was 3.8 and 2.1 higher for verapamil and loperamide, respectively (16). Consequently, the metoclopramide brain-to-plasma ratio was 1.2 in wild-type mice compared with 0.34 and 0.55 for verapamil and loperamide, respectively (20). Recent proteomic data have elucidated the transporter expression pattern at the rodent and human BBB: P-gp and BCRP are the main ABC transporters of pharmacokinetic importance at the $\mathrm{BBB}$ where the multidrug resistance protein 1 (MRP1, ABCC1) was not detected (21). Our in vitro data suggest that ${ }^{11} \mathrm{C}$-metoclopramide is not likely to be influenced by BCRP function at the BBB.

Dedicated P-gp substrates with substantial baseline brain distribution are necessary to elucidate the specific features of Pgp function on the brain kinetics of CNS drugs (2). ${ }^{18} \mathrm{~F}-\mathrm{MPPF}$
( $2^{\prime}$-methoxyphenyl-( $N$-2' -pyridinyl)-p- ${ }^{18}$ F-fluoro-benzamidoethylpiperazine), a clinically validated serotoninergic $5-\mathrm{HT}_{1 \mathrm{~A}}$ receptor antagonist, was proposed to study P-gp function at the rodent BBB (22). Unfortunately, this ligand is not transported by human P-gp (19). Transport of the antiepileptic drug phenytoin by the human P-gp was shown to be extremely weak compared with the rodent isoform $(23,24)$ and is hardly detected using a bidirectional transport assay (16). ${ }^{11} \mathrm{C}$-phenytoin PET is nonetheless an elegant strategy to study antiepileptic drug disposition in the brains of patients with pharmacoresistant epilepsy, which may involve parameters other than P-gp at the BBB $(25,26)$.

Metoclopramide is a dopamine $\mathrm{D}_{2}$ receptor antagonist in vitro $\left(\mathrm{K}_{\mathrm{d}}=46 \mathrm{nM}\right)(27) .{ }^{11} \mathrm{C}$-metoclopramide brain distribution appeared homogeneous with no specific retention in $\mathrm{D}_{2}$-rich regions such as the striatum, even in the absence of P-gp inhibition (Fig. 2). Maximal metoclopramide concentrations in the brain obtained using microdose injection was approximately $20 \mathrm{pmol} \cdot \mathrm{mL}^{-1}$ versus approximately $13 \mathrm{nmol} \cdot \mathrm{mL}^{-1}$ using the coinjection protocol, allowing

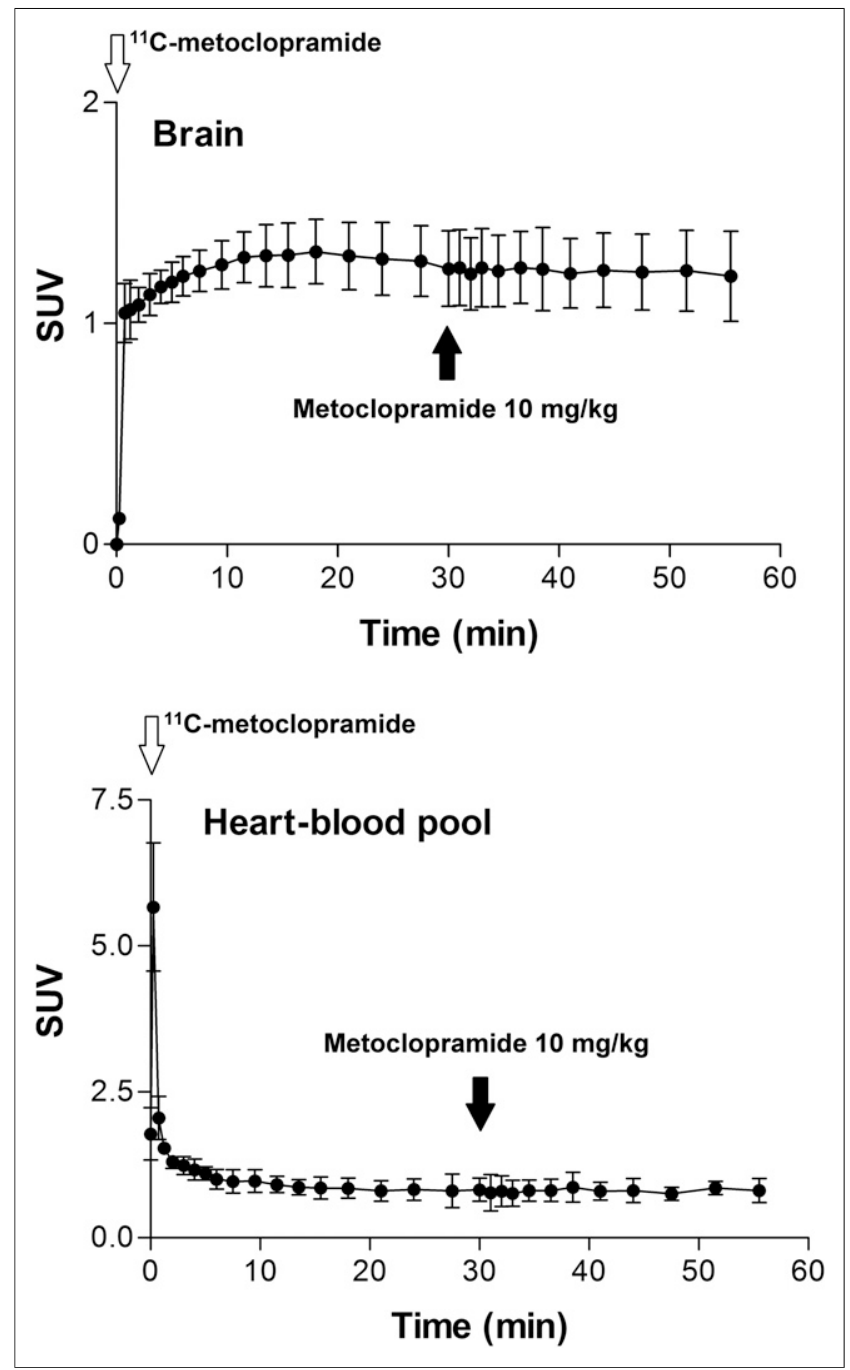

FIGURE 4. Displacement experiments performed in P-gp-inhibited rats: time-activity curves obtained in brain and heart blood-pool. $\mathrm{P}$-gp-inhibited rats were injected with ${ }^{11} \mathrm{C}$-metoclopramide $(42.5 \pm$ $6.4 \mathrm{MBq}$ ) along with metoclopramide, $3 \mathrm{mg} / \mathrm{kg}$ (condition $\mathrm{D}$ ). Additional dose of metoclopramide $(10 \mathrm{mg} / \mathrm{kg})$ was injected at $30 \mathrm{~min}$. 
TABLE 1

${ }^{11} \mathrm{C}-$ Metoclopramide Outcome Parameters Estimated in Rat Brain in Each Condition Using Logan Plot Analysis and 2Tissue-Compartment Model

\begin{tabular}{|c|c|c|c|c|c|c|c|c|c|}
\hline \multirow[b]{2}{*}{ Condition } & \multirow[b]{2}{*}{$n$} & \multirow[b]{2}{*}{$f_{p}(\%)$} & \multicolumn{2}{|c|}{ Logan plot } & \multicolumn{5}{|c|}{ 2-tissue-compartment model } \\
\hline & & & $\begin{array}{l}\mathrm{V}_{\mathrm{T}}\left(\mathrm{mL} \cdot \mathrm{cm}^{-3}\right) \\
\text { using arterial } \\
\text { input function }\end{array}$ & $\begin{array}{c}\mathrm{V}_{\mathrm{T}}^{\prime}\left(\mathrm{mL} \cdot \mathrm{cm}^{-3}\right) \text { using } \\
\text { image-derived } \\
\text { input function }\end{array}$ & $\begin{array}{c}K_{1} \\
\left(\mathrm{~mL} \cdot \mathrm{cm}^{-3} \cdot \mathrm{min}^{-1}\right)\end{array}$ & $k_{2}\left(\min ^{-1}\right)$ & $k_{3}\left(\min ^{-1}\right)$ & $k_{4}\left(\min ^{-1}\right)$ & $\mathrm{BP}_{\mathrm{ND}}$ \\
\hline$A$ & 5 & $12.0 \pm 1.9$ & $2.28 \pm 0.32$ & $2.46 \pm 0.70$ & $0.23 \pm 0.11$ & $0.35 \pm 0.18$ & $0.22 \pm 0.12$ & $0.09 \pm 0.03$ & $2.40 \pm 0.78$ \\
\hline$B$ & 4 & $14.8 \pm 5.7$ & $7.80 \pm 1.43^{\star}$ & $8.33 \pm 0.91^{*}$ & $1.02 \pm 0.34^{\star}$ & $0.66 \pm 0.20$ & $0.34 \pm 0.09$ & $0.06 \pm 0.02$ & $5.44 \pm 0.50^{\star}$ \\
\hline C & 4 & $12.4 \pm 3.0$ & $2.04 \pm 0.19$ & $2.41 \pm 0.29$ & $0.36 \pm 0.12$ & $0.43 \pm 0.10$ & $0.22 \pm 0.15$ & $0.09 \pm 0.03$ & $2.21 \pm 1.04$ \\
\hline $\mathrm{D}$ & 5 & $16.7 \pm 7.4$ & $6.28 \pm 0.48^{\dagger, \ddagger}$ & $7.13 \pm 0.35^{\dagger, \emptyset}$ & $0.73 \pm 0.11^{\dagger}$ & $0.20 \pm 0.06^{\dagger, \uparrow}$ & $0.10 \pm 0.06$ & $0.07 \pm 0.02$ & $1.97 \pm 0.40^{9}$ \\
\hline
\end{tabular}

*Statistical significance, $P<0.05$ for conditions $\mathrm{B}$ and $\mathrm{C}$ compared with condition A.

${ }^{\dagger}$ Statistical significance, $P<0.05$ for condition D compared with condition C.

"Statistical significance, $P<0.05$, and $¥ P<0.01$ for condition $\mathrm{D}$ compared with condition $\mathrm{B}$.

Data are shown as mean $\pm S D$ in each condition, $n$ is number of animals used in each group, and $f_{P}$ is percentage of free ${ }^{11} C$ metoclopramide in plasma. Logan plot analysis was used to estimate total distribution volume using arterial input function $\left(\mathrm{V}_{\mathrm{T}}\right)$ or image-derived input function $\left(\mathrm{V}_{\mathrm{T}}^{\prime}\right)$. 2-tissue-compartment model was used to estimate ${ }^{11} \mathrm{C}$-metoclopramide $K_{1}, k_{2}, k_{3}, k_{4}$, and $\mathrm{BP}_{\mathrm{ND}}$.

for substantial $\mathrm{D}_{2}$ receptor occupancy $\left(\mathrm{B}_{\max }=68 \mathrm{pmol} \cdot \mathrm{mL}^{-1}\right)$ (28). High-dose metoclopramide $(5.6 \mathrm{mg} / \mathrm{kg})$ is necessary to displace ${ }^{3} \mathrm{H}$-spiperone from $\mathrm{D}_{2}$ receptor binding in rats (29). In condition $\mathrm{D}$, additional displacement experiments using $10 \mathrm{mg} / \mathrm{kg}$ showed that ${ }^{11} \mathrm{C}$-metoclopramide binding to the brain is mainly nonspecific (Fig. 4). Metoclopramide binding to the brain is reversible $\left(k_{4}>0\right)$, and its mechanism is unknown. Metoclopramide is a tertiary amine and part of the binding may involve lysosomal trapping, as reported for ${ }^{11} \mathrm{C}-\mathrm{N}$-desmethyl-loperamide (30).

Using microdose ${ }^{11} \mathrm{C}$-metoclopramide, we found that $\mathrm{P}$-gp inhibition increased $\mathrm{V}_{\mathrm{T}}, K_{1}$, and $\mathrm{BP}_{\mathrm{ND}}$ (Table 1). The effect on $\mathrm{BP}_{\mathrm{ND}}$ was observed using ${ }^{11} \mathrm{C}$-verapamil (31) and ${ }^{18} \mathrm{~F}-\mathrm{MPPF}$ (22). This effect suggests that ${ }^{11} \mathrm{C}$-metoclopramide binding to the brain competes with P-gp-mediated efflux, which complicates the interpretation of kinetic analysis results. In the pharmacologic situation, $\mathrm{P}$-gp inhibition did not affect $\mathrm{BP}_{\mathrm{ND}}$, allowing for a straight comparison of ${ }^{11} \mathrm{C}$-metoclopramide transfer across the BBB $\left(K_{1}\right.$ and $k_{2}$ ). This also ensures that $\mathrm{V}_{\mathrm{T}}$ specifically reflects metoclopramide transport through the BBB and can be used as an outcome parameter to quantify the impact of P-gp function at the BBB. Baseline ${ }^{11} \mathrm{C}$-metoclopramide $\mathrm{V}_{\mathrm{T}}$ and $\mathrm{BP}_{\mathrm{ND}}$ were not different with or without unlabeled metoclopramide (Table 1), suggesting that metoclo-

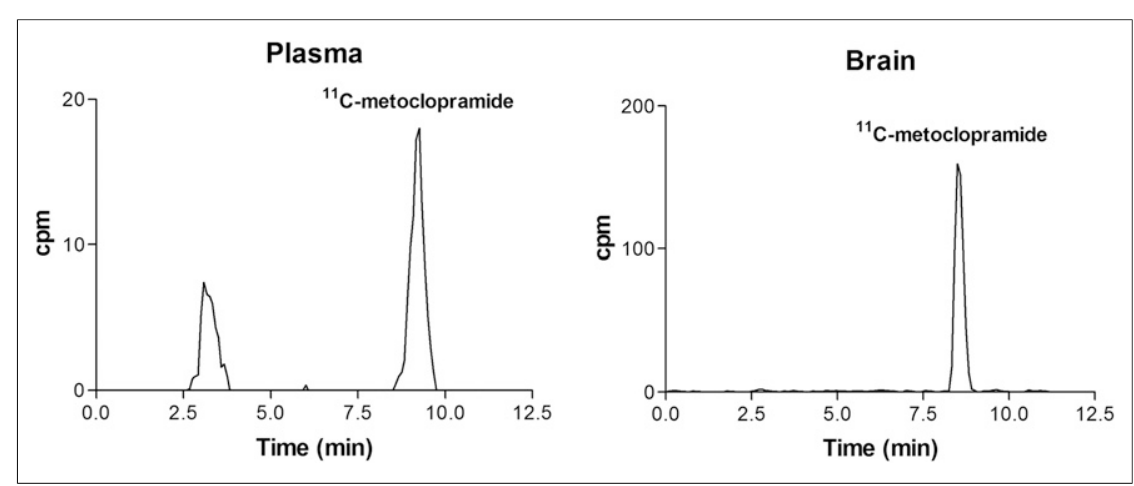

FIGURE 5. Representative radio-high-performance liquid chromatograms obtained in plasma and in brain of P-gp-inhibited rats 30 min after ${ }^{11} \mathrm{C}$-metoclopramide injection (condition D, 70 $\mathrm{MBq} ; 3 \mathrm{mg} / \mathrm{kg}$ ). pramide does not saturate its own transport at the BBB up to $3 \mathrm{mg} / \mathrm{kg}$.

When pharmacologic-dose metoclopramide was used, P-gp inhibition resulted in a delayed brain $\mathrm{T}_{\max }$ followed by slower washout from the brain (Fig. 3) and a decrease in $k_{2}$ in addition to an increase in $K_{1}$. Once in the brain, P-gp therefore seems to promote efflux back to the blood. This phenomenon was actually previously shown in rats using an invasive approach, taking brain metabolites into account $(8,32)$.

The potential interaction of undercurrent treatments or genetic polymorphism on radiotracer peripheral pharmacokinetics is a major issue for PET data interpretation $(33,34)$. Coinjection with unlabeled metoclopramide increased ${ }^{11} \mathrm{C}$-metoclopramide plasma exposure (Fig. 3). Baseline ${ }^{11} \mathrm{C}$-metoclopramide brain kinetics estimated using metabolite-corrected input function were not influenced by the extent of metabolite formation. This result can be explained by the negligible brain distribution of plasma radiometabolites (Fig. 5), resulting in the suitable radiochemical purity of ${ }^{11} \mathrm{C}$-metoclopramide brain signal. We showed that P-gp function is not responsible for the negligible brain permeation of ${ }^{11} \mathrm{C}$-metoclopramide radiometabolites.

Modulation of P-gp function at the BBB, due to genetic polymorphism (35), environmental factors (36), or drug-drug interactions (37), may contribute to interindividual variability of brain exposure and subsequent pharmacodynamic response to CNS drugs, including pharmacoresistance (36). $K_{1}$ is estimated in the early distribution phase, where P-gp works against the concentration gradient between the plasma and the brain (12). Our study suggests that ignoring the brain efflux component $\left(k_{2}\right)$ may underestimate the overall contribution of P-gp on CNS drug exposure to the brain $(9,34,38)$. Given the absence of brain radiometabolites, ${ }^{11} \mathrm{C}$-metoclopramide coinjected with metoclopramide allows for the reliable and noninvasive estimation of $k_{2}$ in vivo. This relevant outcome parameter 
may be useful to describe the impact of P-gp modulation on the brain kinetics of drugs.

The development of PET imaging approaches in humans has raised new opportunities to study $\mathrm{P}$-gp function in situations in which this transporter may be overexpressed (36). Current protocols focusing on influx hindrance require partial $\mathrm{P}$-gp inhibition to achieve substantial ${ }^{11} \mathrm{C}$-verapamil baseline $K_{1}(34,38)$. To that end, potent P-gp inhibitors such as tariquidar are not readily available, especially for human use. It can be hypothesized that P-gp induction enhances drug efflux from the brain $\left(k_{2}\right)$ in addition to its impact on previously reported influx hindrance $\left(K_{1}\right)$.

\section{CONCLUSION}

${ }^{11} \mathrm{C}$-metoclopramide PET imaging was used to investigate the overall impact of P-gp function on the brain kinetics of metoclopramide, a prototypical CNS drug with substantial brain distribution. We demonstrated that P-gp controls both the influx and the efflux of drugs across the BBB. This PET-based strategy may provide novel insight on the role of $\mathrm{P}-\mathrm{gp}$ at the $\mathrm{BBB}$ in healthy and diseased situations.

\section{DISCLOSURE}

The costs of publication of this article were defrayed in part by the payment of page charges. Therefore, and solely to indicate this fact, this article is hereby marked "advertisement" in accordance with 18 USC section 1734 . No potential conflict of interest relevant to this article was reported.

\section{ACKNOWLEDGMENTS}

We thank Sanofi for kindly providing the radiolabeling precursor and Dr. Alfred Schinkel for the MDCKII cells. We thank Héric Valette, Catriona Wimberley, and Michel Bottlaender for helpful discussions.

\section{REFERENCES}

1. Abbott NJ, Patabendige AAK, Dolman DEM, Yusof SR, Begley DJ. Structure and function of the blood-brain barrier. Neurobiol Dis. 2010;37:13-25.

2. Wanek T, Mairinger S, Langer O. Radioligands targeting P-glycoprotein and other drug efflux proteins at the blood-brain barrier. J Labelled Comp Radiopharm. 2013;56:68-77.

3. Sasongko L, Link JM, Muzi M, et al. Imaging P-glycoprotein transport activity at the human blood-brain barrier with positron emission tomography. Clin Pharmacol Ther. 2005;77:503-514.

4. Luurtsema G, Molthoff CFM, Schuit RC, Windhorst AD, Lammertsma AA, Franssen EJF. Evaluation of (R)-[ $\left.{ }^{11} \mathrm{C}\right]$ verapamil as PET tracer of P-glycoprotein function in the blood-brain barrier: kinetics and metabolism in the rat. Nucl Med Biol. 2005;32:87-93.

5. Lazarova N, Zoghbi SS, Hong J, et al. Synthesis and evaluation of $\left[\mathrm{N}-\right.$ methyl- ${ }^{11} \mathrm{C}$ ] $\mathrm{N}$-desmethyl-loperamide as a new and improved PET radiotracer for imaging P-gp function. J Med Chem. 2008;51:6034-6043.

6. Kannan P, John C, Zoghbi SS, et al. Imaging the function of P-glycoprotein with radiotracers: pharmacokinetics and in vivo applications. Clin Pharmacol Ther. 2009;86:368-377.

7. Traxl A, Wanek T, Mairinger S, et al. Breast cancer resistance protein and P-glycoprotein influence in vivo disposition of ${ }^{11} \mathrm{C}$-erlotinib. $J$ Nucl Med. September 10, 2015 [Epub ahead of print].

8. Westerhout J, Smeets J, Danhof M, de Lange ECM. The impact of P-gp functionality on non-steady state relationships between CSF and brain extracellular fluid. J Pharmacokinet Pharmacodyn. 2013;40:327-342.

9. Syvänen S, Xie R, Sahin S, Hammarlund-Udenaes M. Pharmacokinetic consequences of active drug efflux at the blood-brain barrier. Pharm Res. 2006;23:705-717.

10. Sander K, Galante E, Gendron T, et al. Development of fluorine-18 labeled metabolically activated tracers for imaging of drug efflux transporters with positron emission tomography. J Med Chem. 2015;58:6058-6080.

11. Potschka H. Role of CNS efflux drug transporters in antiepileptic drug delivery: overcoming CNS efflux drug transport. Adv Drug Deliv Rev. 2012;64:943-952.
12. Tournier N, Declèves X, Saubaméa B, Scherrmann J-M, Cisternino S. Opioid transport by ATP-binding cassette transporters at the blood-brain barrier: implications for neuropsychopharmacology. Curr Pharm Des. 2011;17:2829-2842.

13. Akamine Y, Yasui-Furukori N, Ieiri I, Uno T. Psychotropic drug-drug interactions involving P-glycoprotein. CNS Drugs. 2012;26:959-973.

14. Lee A, Kuo B. Metoclopramide in the treatment of diabetic gastroparesis. Expert Rev Endocrinol Metab. 2010;5:653-662.

15. Liu X, Van Natta K, Yeo H, et al. Unbound drug concentration in brain homogenate and cerebral spinal fluid at steady state as a surrogate for unbound concentration in brain interstitial fluid. Drug Metab Dispos. 2009;37:787-793.

16. Feng B, Mills JB, Davidson RE, et al. In vitro P-glycoprotein assays to predict the in vivo interactions of P-glycoprotein with drugs in the central nervous system. Drug Metab Dispos. 2008;36:268-275.

17. Tournier N, Valette H, Peyronneau M-A, et al. Transport of selected PET radiotracers by human P-glycoprotein (ABCB1) and breast cancer resistance protein (ABCG2): an in vitro screening. J Nucl Med. 2011;52:415-423.

18. Bakhsheshian J, Hall MD, Robey RW, et al. Overlapping substrate and inhibitor specificity of human and murine ABCG2. Drug Metab Dispos. 2013;41:1805-1812.

19. Tournier N, Cisternino S, Peyronneau M-A, et al. Discrepancies in the P-glycoprotein-mediated transport of ${ }^{18} \mathrm{~F}-\mathrm{MPPF}$ : a pharmacokinetic study in mice and non-human primates. Pharm Res. 2012;29:2468-2476.

20. Doran A, Obach RS, Smith BJ, et al. The impact of P-glycoprotein on the disposition of drugs targeted for indications of the central nervous system: evaluation using the MDR1A/1B knockout mouse model. Drug Metab Dispos. 2005;33:165-174.

21. Ohtsuki S, Hirayama M, Ito S, Uchida Y, Tachikawa M, Terasaki T. Quantitative targeted proteomics for understanding the blood-brain barrier: towards pharmacoproteomics. Expert Rev Proteomics. 2014;11:303-313.

22. Laćan G, Plenevaux A, Rubins DJ, et al. Cyclosporine, a P-glycoprotein modulator, increases $\left[{ }^{18} \mathrm{~F}\right] \mathrm{MPPF}$ uptake in rat brain and peripheral tissues: microPET and ex vivo studies. Eur J Nucl Med Mol Imaging. 2008;35:2256-2266.

23. Baltes S, Gastens AM, Fedrowitz M, Potschka H, Kaever V, Löscher W. Differences in the transport of the antiepileptic drugs phenytoin, levetiracetam and carbamazepine by human and mouse P-glycoprotein. Neuropharmacology. 2007;52:333-346.

24. Luna-Tortós C, Fedrowitz M, Löscher W. Several major antiepileptic drugs are substrates for human P-glycoprotein. Neuropharmacology. 2008;55:1364-1375.

25. Kwan P, Schachter SC, Brodie MJ. Drug-resistant epilepsy. $N$ Engl J Med. 2011;365:919-926.

26. Mansor S, Boellaard R, Froklage FE, et al. Quantification of dynamic ${ }^{11} \mathrm{C}$-phenytoin PET studies. J Nucl Med. 2015;56:1372-1377.

27. Woodward R, Daniell SJ, Strange PG, Naylor LH. Structural Studies on D2 dopamine receptors: mutation of a histidine residue specifically affects the binding of a subgroup of substituted benzamide drugs. J Neurochem. 1994;62:1664-1669.

28. Mauger G, Saba W, Hantraye P, et al. Multiinjection approach for D2 receptor binding quantification in living rats using $\left[{ }^{11} \mathrm{C}\right]$ raclopride and the beta-microprobe: crossvalidation with in vitro binding data. J Cereb Blood Flow Metab. 2005;25:1517-1527.

29. Chivers JK, Reavill C, Jenner P, Marsden CD. Definition of the in-vivo binding of $\left[{ }^{3} \mathrm{H}\right]$ spiperone in rat brain using substituted benzamide drugs. J Pharm Pharmacol. 1989;41:106-111.

30. Kannan P, Brimacombe KR, Kreisl WC, et al. Lysosomal trapping of a radiolabeled substrate of P-glycoprotein as a mechanism for signal amplification in PET. Proc Natl Acad Sci USA. 2011;108:2593-2598.

31. Muzi M, Mankoff DA, Link JM, et al. Imaging of cyclosporine inhibition of P-glycoprotein activity using ${ }^{11} \mathrm{C}$-verapamil in the brain: studies of healthy humans. J Nucl Med. 2009;50:1267-1275.

32. Müllauer J, Kuntner C, Bauer M, et al. Pharmacokinetic modeling of P-glycoprotein function at the rat and human blood-brain barriers studied with $(\mathrm{R})-\left[{ }^{11} \mathrm{C}\right]$ verapamil positron emission tomography. EJNMMI Res. 2012;2:58.

33. Abrahim A, Luurtsema G, Bauer M, et al. Peripheral metabolism of $(R)-\left[{ }^{11} \mathrm{C}\right]$ verapamil in epilepsy patients. Eur J Nucl Med Mol Imaging. 2008;35:116-123.

34. Feldmann M, Asselin M-C, Liu J, et al. P-glycoprotein expression and function in patients with temporal lobe epilepsy: a case-control study. Lancet Neurol. 2013;12:777-785.

35. Giacomini KM, Balimane PV, Cho SK, et al. International transporter consortium commentary on clinically important transporter polymorphisms. Clin Pharmacol Ther. 2013;94:23-26.

36. Miller DS. Regulation of ABC transporters blood-brain barrier: the good, the bad, and the ugly. Adv Cancer Res. 2015;125:43-70.

37. König J, Müller F, Fromm MF. Transporters and drug-drug interactions: important determinants of drug disposition and effects. Pharmacol Rev. 2013;65:944-966.

38. Bankstahl JP, Bankstahl M, Kuntner C, et al. A novel positron emission tomography imaging protocol identifies seizure-induced regional overactivity of P-glycoprotein at the blood-brain barrier. J Neurosci. 2011;31:8803-8811. 